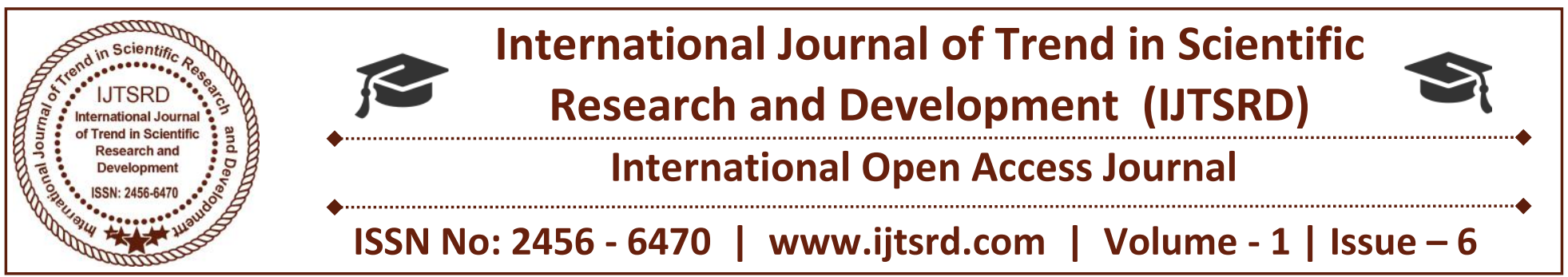

\title{
Effectiveness of Structured Teaching Programme on Knowledge Regarding Osteoporosis and Its Management Among Menopausal Women
}

\author{
Ravi Kulal \\ Associate Professor, Maharaja \\ Agrasen College of Nursing, \\ Gurugram, Haryana
}

\author{
Shweta Handa \\ Assistant Professor, Faculty of \\ Nursing, SGT University, \\ Gurugram, Haryana
}

\author{
Rashmi Negi \\ Assistant Professor, Faculty of \\ Nursing, SGT University, \\ Gurugram, Haryana
}

\section{ABSTRACT}

Osteoporosis is an established and well-defined disease that affects millions of people around the world and is a major cause of morbidity osteoporosis is a major public health threat for an estimated 44 million American or 55 percent of the people 50years of age and older, in the US 10 million individuals are estimated to already have the disease and almost 31 million move are estimated to have low bone mass, placing them at increased risk for osteoporosis multiple compression fractures of the vertebrae result in skeletal deformity, osteoporosis is a costly disorder not only in terms of health care dollars but also in terms of human suffering, pain, disability and death. A Pre-experimental research design was used for the study. Self prepared knowledge questionnaire was administered to 50 menopausal women based on Nonprobability purposive sampling technique.

Findings of the present study shows that, highest percentage $(78 \%)$ of the sample had an average level of knowledge whose score ranged between 10-18, $22 \%$ of the sample had good knowledge whose score ranged between 19-28 and $0 \%$ of the sample had poor knowledge regarding osteoporosis and its management. The mean percentage of total pre-test knowledge score was $58.29 \%$ with mean \pm SD 16.32 \pm 3.172. Findings also show that, $100 \%$ of menopausal women had good knowledge regarding osteoporosis and its management in the post-test whose score ranged between 20-30. The mean percentage of total post-test knowledge score was $79.57 \%$ with mean \pm SD $22.28 \pm 2$.

Keywords: Structured teaching programme, menopausal women regarding, osteoporosis, Knowledge Effectiveness

\section{INTRODUCTION}

The Women's body is wonderfully complex \& delicate, however, multiple voles as the mother daughter, wife homemaker, wage earner can be physically \& mentally quite taxing, poverty tends to yield a higher burden on women \& girls health ${ }^{1}$. Women is a "Angel of mercy". Bone begins to form long before birth, ossification is the process by which the bone matrix (collages fibers \& ground substance) is formed \&hardening minerals (eg. Calcium salts) are deposited on the collages fibers. The collages fibers give tensile strength to the bone and the calcium provides compressional strength. The important regulating factors that determine the balance between bone formation and bone resorption include local stress, Vitamin-D, parathyroid hormone, calicitonin ${ }^{2}$.

Osteoporosis or porous bone, is a disease characterized by low bone mass and structural deterioration of bone tissue leading to bone fragility and an increased susceptibility to fractures. The 
normal homeostatic bone turnover is altered, the rate of bone resorption is greater than the rate of bone formation, resulting in a reduced total bone mass suboptimal bone mass development in children and teens contributes to the development of osteoporosic with osteoporosis the bone becomes progressively porous brittle and fragile they fracture easily under stresses that would not break normal bone. Osteoporosis frequently results in compression factors of the thoracic and lumbar spine, factors of the neck and intertrochanteric region of the femur and collies fractures of the wrist. ${ }^{2}$

Osteoporosis is an established and well-defined disease that affects millions of people around the world and is a major cause of morbidity osteoporosis is a major public health threat for an estimated 44 million American or 55 percent of the people 50years of age and older, in the US 10 million individuals are estimated to already have the disease and almost 31 million move are estimated to have low bone mass, placing them at increased risk for osteoporosis multiple compression fractures of the vertebrae result in skeletal deformity, osteoporosis is a costly disorder not only in terms of health care dollars but also in terms of human suffering, pain, disability and death. ${ }^{2}$ The gradual collapse of a vertebra may be a symptomatic it is observed as progressive kypnosis with the development of kyphosis there is an associated loss of height frequently postmenopausal women lose height from vertebral collapse. The postural change results in relaxation of the abdominal muscles and a protruding abdomen. The deformity may also produce pulmonary insufficiency. Many patients complain of fatigue. ${ }^{3}$

Osteoporosis is often thought of as an older person's disease, it can strike at any age women, $80 \%$ of those affected by osteoporosis are women. Twenty percent of non Hispanic white and Asian women aged sot and older are estimated to have osteoporosis and 52 percent are estimated to have low bone mass. Five percent of non Hispanic black women over age 50 are estimated to have osteoporosis. Ten percent of Hispanic women aged 50 and older are estimated to have osteoporosis and 79 percent are estimated to have low bone mass osteoporosis is under recognized and under treated not only in Caucasian women but in African - American women as well. ${ }^{4}$

Osteoporosis is often called a "silent disease" because bone loss occurs without symptoms people may not know that they have osteoporosis until strain, bump or fall causes a fracture or a vertebra to collapse. Collapsed vertebrae may initially be felt or seen in the form of severe back pain, loss of height or spinal deformities such as kyphosis or stooped posture. ${ }^{5}$

\section{Need for the study:}

During childhood and adolescence, bone formation is dominant, bone length and girth increase with age, ending at early adulthood when peak bone mass is attained females tend to maintain peak mineral content until menopause, after which time its declines about $15 \%$ per decade. ${ }^{6}$

Worldwide an osteoporotic fracture is estimated to occur every 3 second, a vertebral fracture every 22 seconds. Osteoporosis is estimated to affect 200 million women worldwide approximately one-tenth of women aged to one-fifth of women aged 70, two fifth of women aged 80 and two-thirds of women aged $90 .^{7}$ Osteoporosis affects an estimated 75 million people in Europe, USA and Japan for the year 2000, there were an estimated 9 million new osteoporotic fractures of which 1-6 million were at the hip, 1.7 million were at the forearm and d1.4 million were clinical vertebral fractures. 1 in 3 women over 50 will expensive osteoporotic fracture $80 \%, 75 \%, 70 \%$ and $58 \%$ of forearm, humerus, hip and spine fractures respectively occur in women, between 1990 and 2000, there was nearly a $25 \%$ increases in hip fractures worldwide by 2050 , the worldwide incidence of hip fracture in women in protected to increase by $310 \%$ and $240 \%$ in women. ${ }^{7}$

In women over 45 years of age, osteoporosis accounts for more days spent in hospital than many other diseases, including diabetes, myocardial infarction and breast cancer. In 2000 there were an estimated 4 million new fractures with 8 fractures each minute or one every 8 seconds. In UK Based on current trends, hip fracture rates may increase from 46,000 in 1985 to 117,000 in 2016. In USA by the year 2010, it is estimated that more than 52 million women and men is this same age category will be affected if current trends continue the figure will climb to more than 61 million by $2020 .^{7}$

In India the Number of osteoporosis patients at approximately 26 million with the numbers projected to increase to 36 million by 2013 . The study among India women aged 30-60 years from low income groups. BMD at all the skeletal sites were much 
lower than values reported from developed countries. With a high prevalence of osteopenia $52 \%$ and osteoporosis $29 \%$ though to be due to inadequate nutrition. ${ }^{8}$

A study was conducted in USA to explore what women from high prevalence rural communities know about osteoporosis and to assess their learning prevalence. A total sample of 437 women in rural were included in this study. The study result showed that the response rate was $93 \%$. The mean age of respondents was 63 years (range 16-95) and 74\% $(n=301)$ of women were post menopausal while $27 \%$ over age $40(n=11)$ reported having a fracture as an adult, less than half of this group $(42 \%, n=47)$ considered themselves at risk for osteoporosis. $42 \%$ $(n=171)$ who rated their knowledge of osteoporosis good or excellent. The study concluded that most women wanted to learn more about osteoporosis \& health care providers remain a preferred source of information. ${ }^{9}$

\section{Problem Statement}

A study to assess the effectiveness of structured teaching programme on knowledge regarding osteoporosis and its management among menopausal women in selected villages of Noida, Uttar Pradesh.

\section{Objectives:}

1. To assess the knowledge of menopausal women regarding osteoporosis and its management.

2. To evaluate the effectiveness of STP regarding osteoporosis and its management in terms of gain in knowledge scores of menopausal women.

3. To find the association of pre-test knowledge scores with selected demographic variables.

\section{Operational Definitions:}

1. Effectiveness: In this study, it refers to the knowledge gain as determined by significant difference in pre-test and pos-test knowledge scores.

2. Structured teaching programme on osteoporosis and its management: In this study, it refers to a systematically prepared teaching programme for menopausal women about the meaning, incidence, types, risk factors, signs and symptoms, complications, diagnosis, and the management of osteoporosis

3. Knowledge: In this study, it refers to the correct response of the subjects to the structured questionnaire schedule related to osteoporosis and its management.

4. Menopausal women: In this study, it refers to women between the age group of 45-65years with permanent cessation of menstruation living in selected villages of Noida, Uttar Pradesh.

\section{MATERIAL \& METHODS:}

\section{Research approach}

An evaluative research approach using the pre-test and post-test was adopted for the study.

\section{Research design}

One group pre-test post-test pre experimental design

\section{Setting}

The present study was conducted in Meramajal and Kallige villages of Pudu community, Noida,Uttar Pradesh.

\section{Population}

The population for the present study comprised of menopausal women between the age group 45- 65 years in the selected villages of Pudu community, Noida,Uttar Pradesh.

\section{Sampling procedure}

A non probability purposive sampling procedure is used to collect the data.

\section{Sample and Sample size}

The sample for the present study was 50 menopausal women from Meramajal and Kallige villages of Pudu community, Noida,Uttar Pradesh who met the criteria.

\section{Sampling Technique}

Non probability purposive sampling technique was adopted for the present study.

\section{RESULTS:}

Description of demographic variables of menopausal women

Age:

The data presented in figure 1 with respect to their age shows that, highest $42 \%$ were in the age group of 45 $50 y e a r s, 38 \%$ were in the age group of 51-55years, $12 \%$ were in the age group of 56-60years and $8 \%$ in 61-65years. 


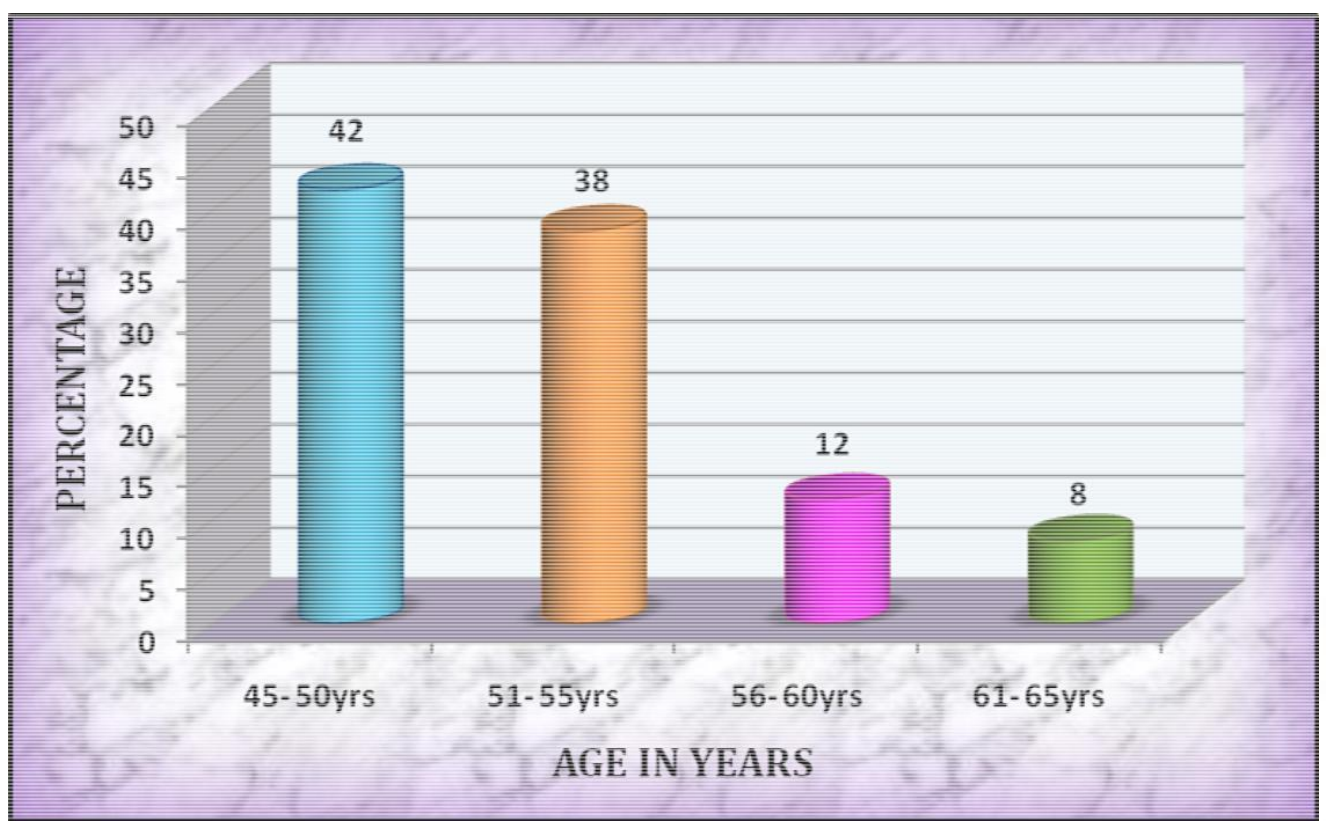

Figure 1: Cylinder diagram showing Percentage distribution of respondents according to their age

\section{Religion}

The data presented in figure 2 with respect to their religion shows that, $50 \%$ were Muslims, $42 \%$ were Hindus, $8 \%$ were Christians and none were of other religions.

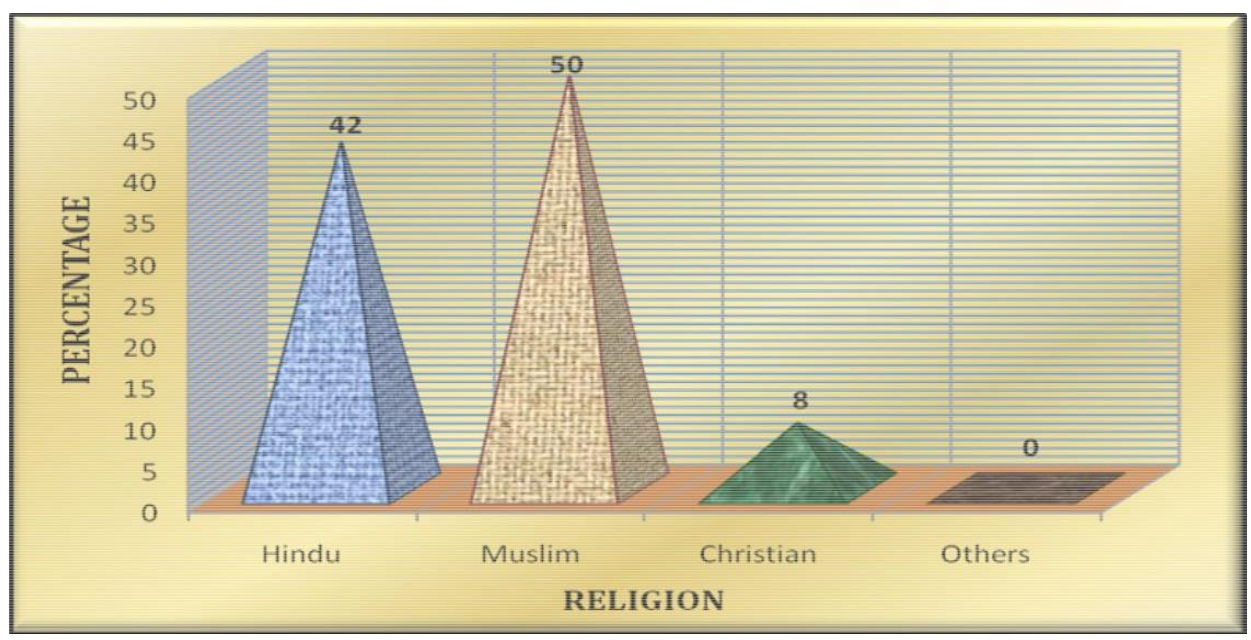

Figure 2: Pyramid diagram showing Percentage distribution of respondents according to their religion

\section{Educational status}

The data presented in figure 3 with respect to their educational status shows that, $46 \%$ of them had primary education, $20 \%$ high school education, $14 \%$ had no formal education, $8 \%$ pre-university education, $6 \%$ graduation, $4 \%$ any other education and $2 \%$ had completed post graduation. 


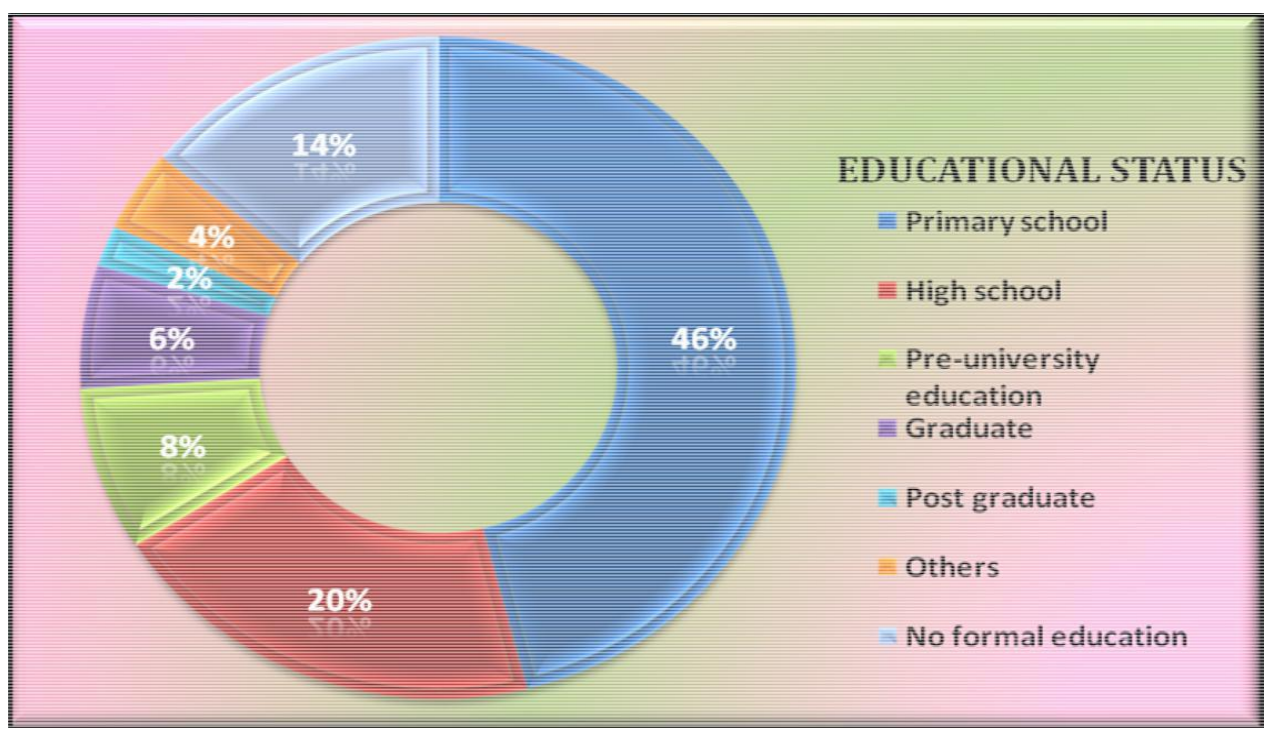

Figure 3: Doughnut diagram showing Percentage distribution of respondents according to their educational status

\section{Occupation}

The data presented in figure 4 with respect to their occupation shows that, $70 \%$ were housewives, $10 \%$ were coolie workers, $8 \%$ were professionals, $6 \%$ were doing business and $6 \%$ other occupations.

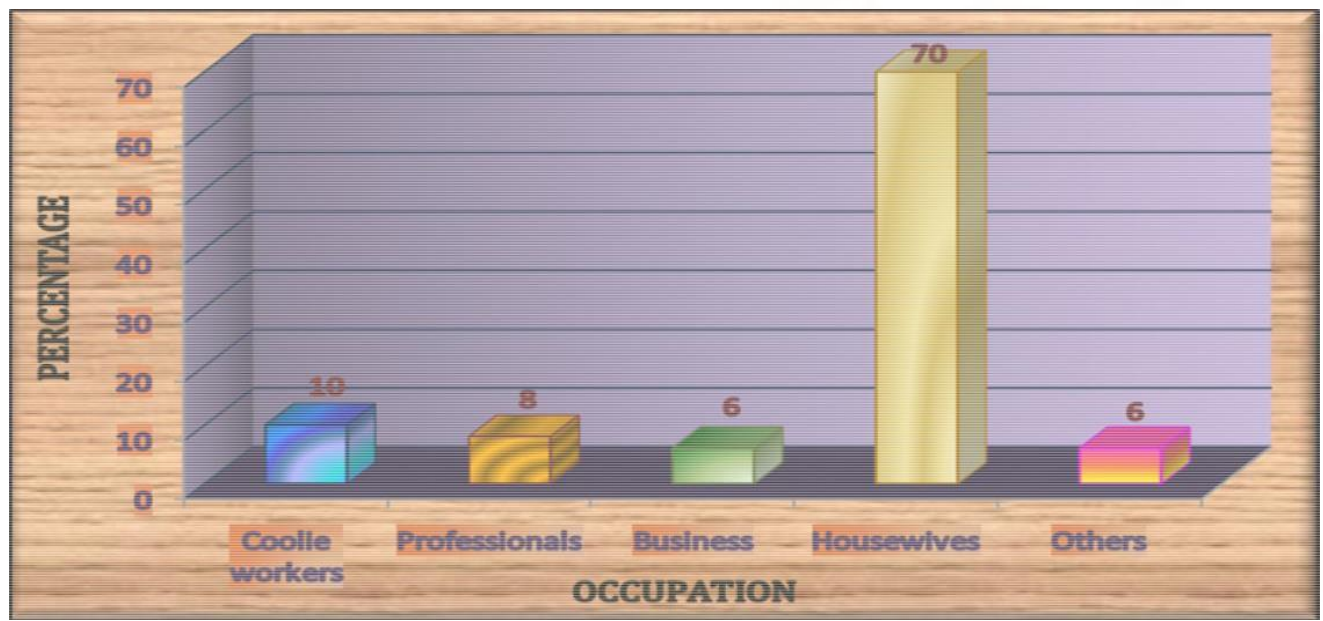

Figure 4: Bar diagram showing Percentage distribution of respondents according to their occupation

\section{Age of menopause}

The data presented in figure 5 with respect to their age of menopause shows that, $64 \%$ had attained menopause at the age of 46-50years, $26 \%$ at the age of 40-45years and the rest $10 \%$ at the age of 51-55years.

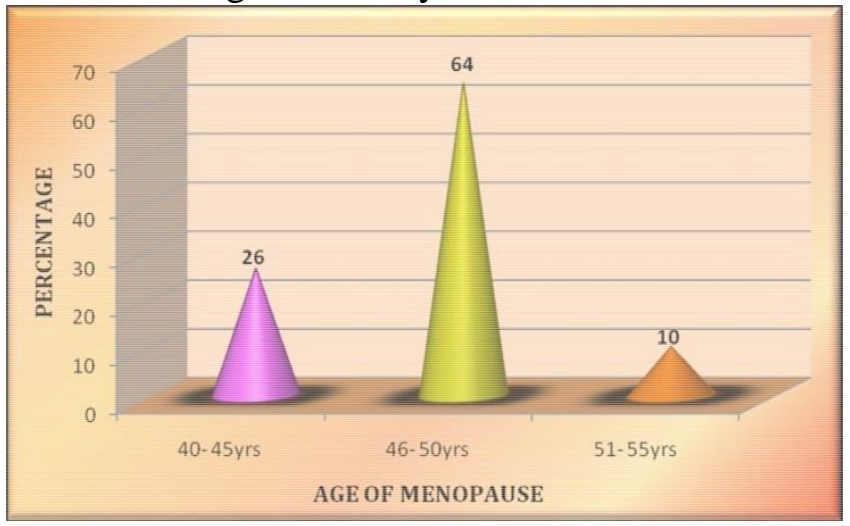


International Journal of Trend in Scientific Research and Development (IJTSRD) ISSN: 2456-6470

Figure 5: Cone diagram showing Percentage distribution of respondents according to their age of menopause

\section{Dietary pattern}

The data presented in figure 6 with respect to their dietary pattern shows that, $92 \%$ were non vegetarians, where as only $8 \%$ were vegetarians.

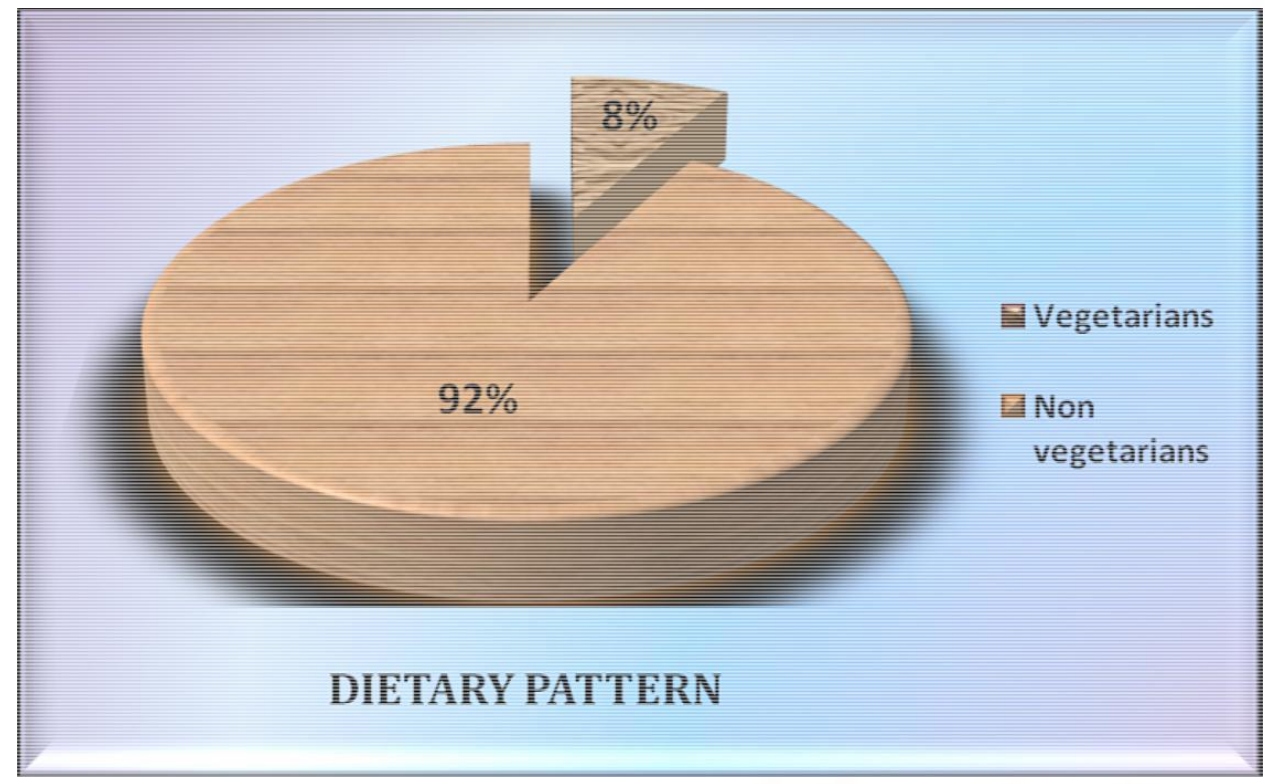

Figure 6: Pie diagram showing Percentage distribution of respondents according to their dietary pattern

\section{Habits}

The data presented in figure 7 with respect to their habits shows that, $80 \%$ didnot have any habits, where as $20 \%$ had the habits like tobacco chewing and alcohol consumption.

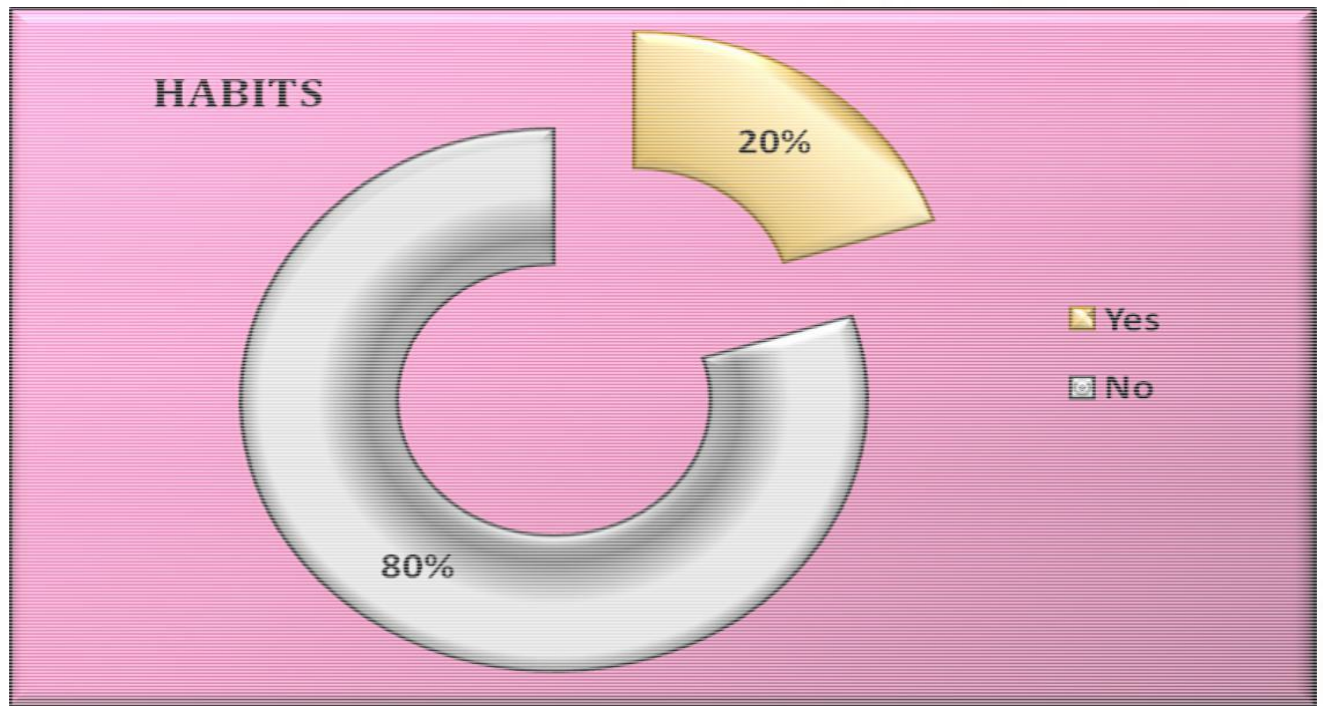

Figure 7: Doughnut diagram showing Percentage distribution of respondents according to their habits

\section{History of bone or joint problem}

The data presented in figure 8 with respect to their history of bone or joint problem shows that, $60 \%$ of women had not suffered from bone or joint problem after menopause, but $40 \%$ of them had the history of bone or joint problem after menopause. 


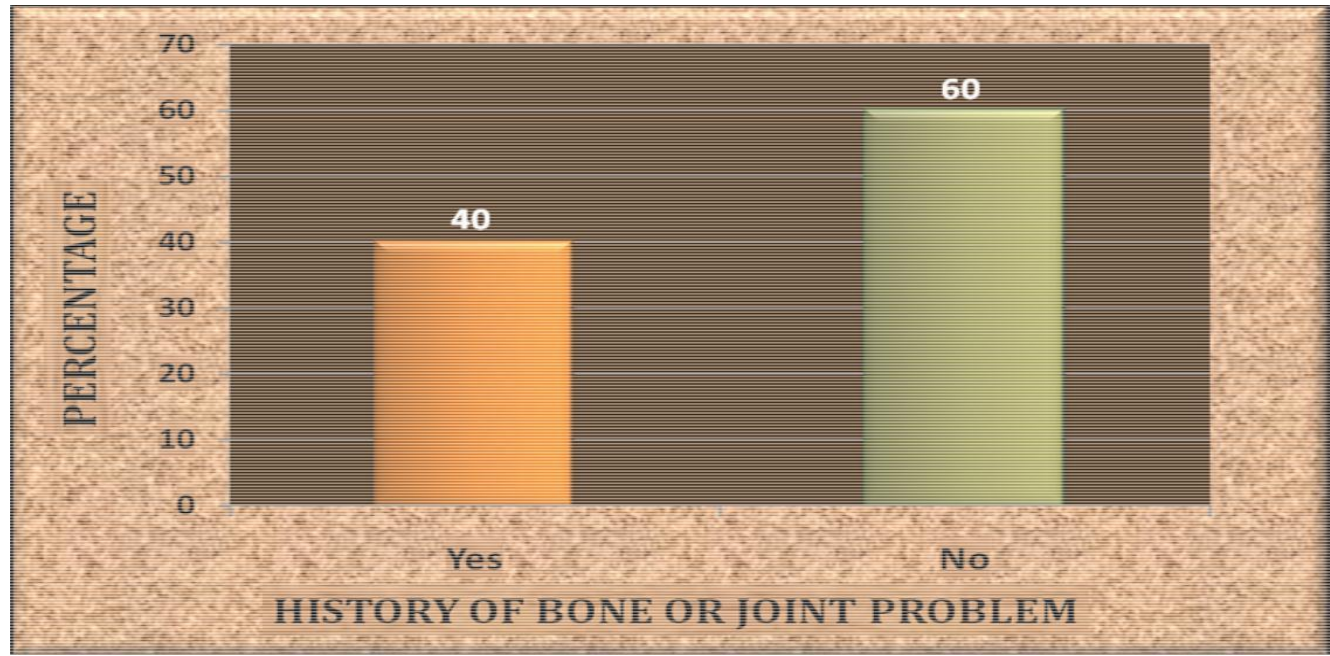

Figure 8: Column diagram showing Percentage distribution of respondents according to their history of bone or joint problem

\section{Previous information about osteoporosis}

Distribution of menopausal women based on the previous information represents that majority (76\%) were not having any information previously, 24\% menopausal women had previous information from mass media, health care professionals, friends and relatives, and other sources.

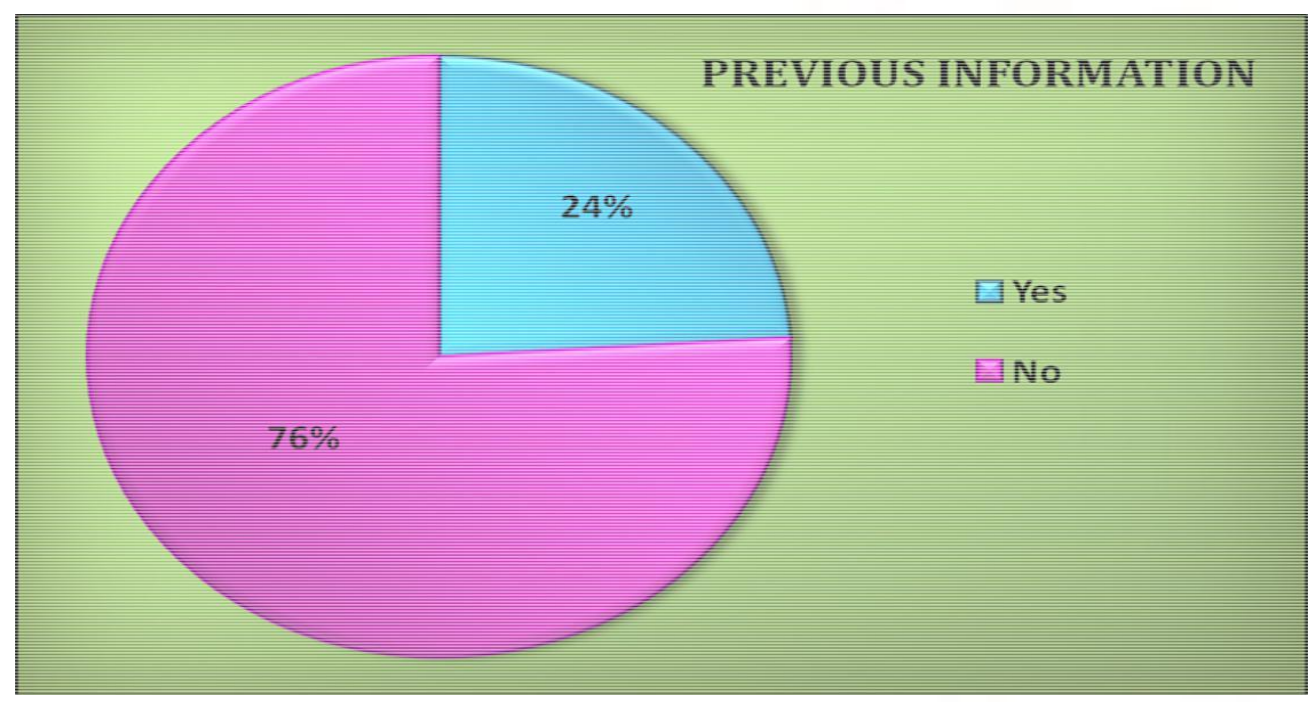

Figure 9: Pie diagram showing Percentage distribution of respondents according to their previous information about Osteoporosis

Level of pre-test knowledge of menopausal women regarding osteoporosis and its management

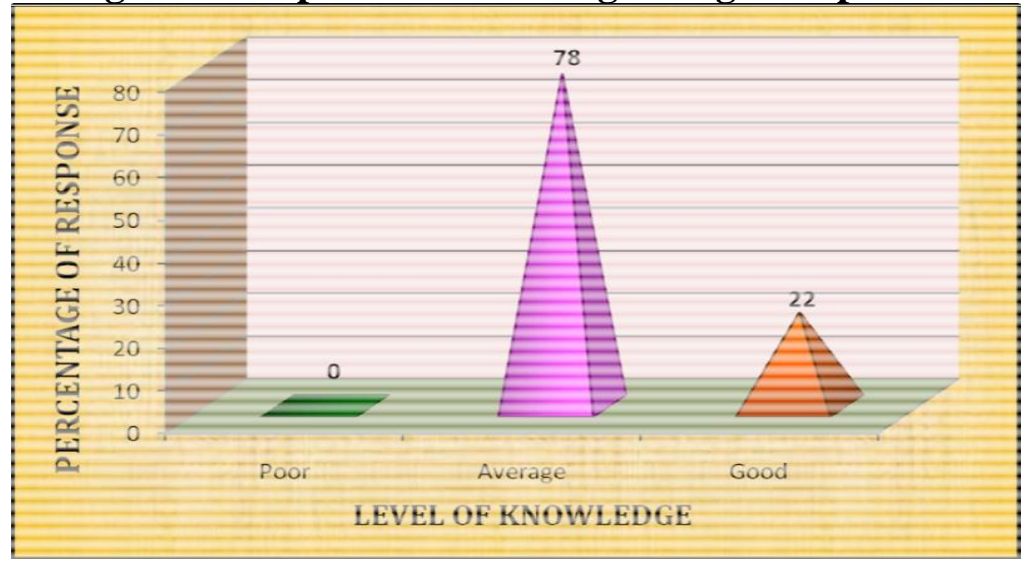


International Journal of Trend in Scientific Research and Development (IJTSRD) ISSN: 2456-6470

Figure 10: Pyramid diagram showing Percentage distribution of respondents according to their level of pre-test knowledge

The above graph shows that the highest percentage (78\%) of the sample had an average level of knowledge whose score ranged between $10-18,22 \%$ of the sample had good knowledge, whereas, $0 \%$ of the sample had poor knowledge regarding osteoporosis and its management. This shows that $78 \%$ of the menopausal women had an average level of knowledge regarding osteoporosis and its management

Section B: Distributions of area-wise mean standard deviation and mean percentage of knowledge scores-pre-test

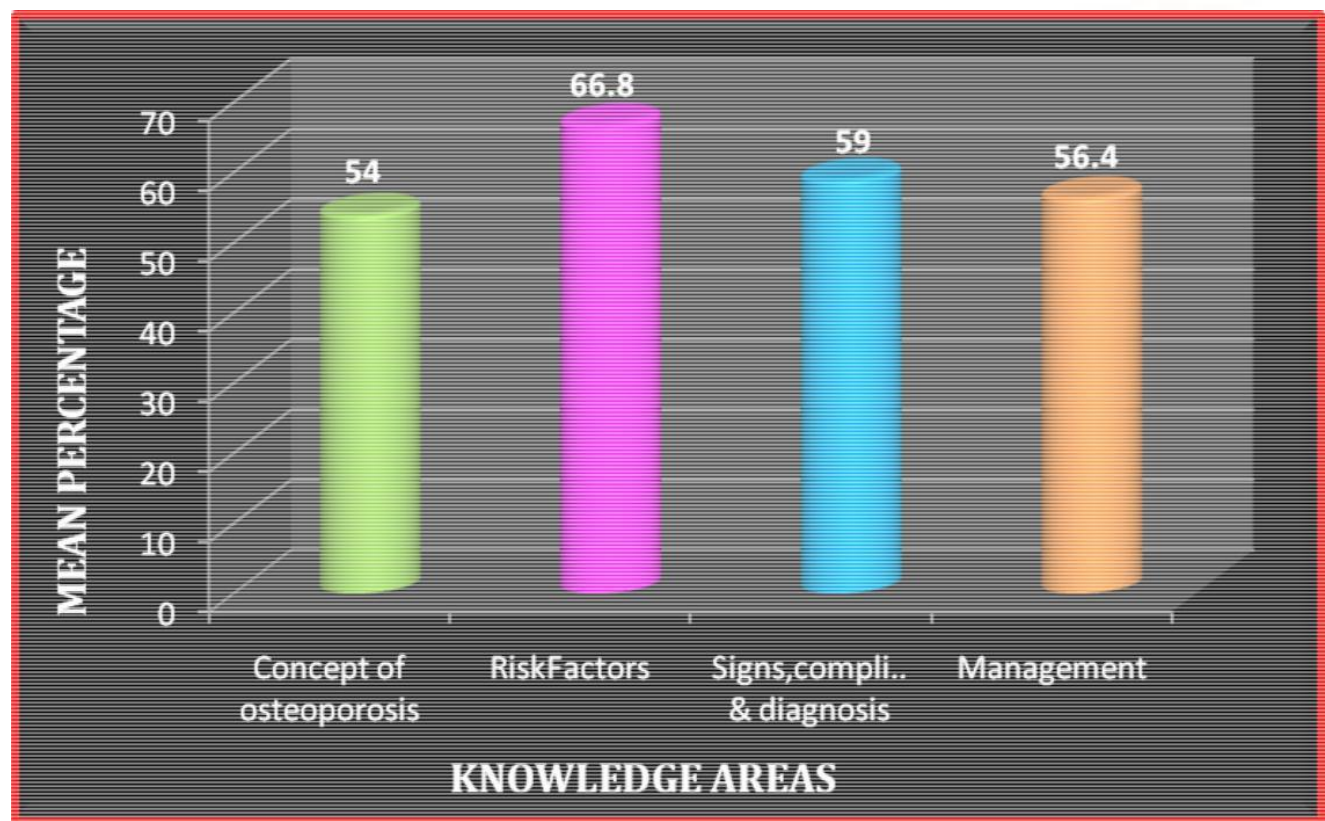

Figure 11: Cylinder diagram showing Percentage distribution of pre-test knowledge score of menopausal women

The above graph shows that the highest mean percentage $(66.8 \%)$ of knowledge score was in the area of "Risk factors of Osteoporosis" which had a mean \pm standard deviation as $3.34 \pm 0.917$. The mean percentage in the area of "Signs and symptoms, complications and diagnosis of Osteoporosis" was 59\% with mean \pm standard deviation as $2.36 \pm 0.722$. The mean percentage in the area of "management of Osteoporosis" was $56.4 \%$ with mean \pm standard deviation as 8.46 \pm 2.102 . The mean percentage in the area of "concept of Osteoporosis" was $54 \%$ with mean \pm standard deviation as $2.16 \pm 0.792$.

\section{Level of post-test knowledge of menopausal women regarding osteoporosis and its management}

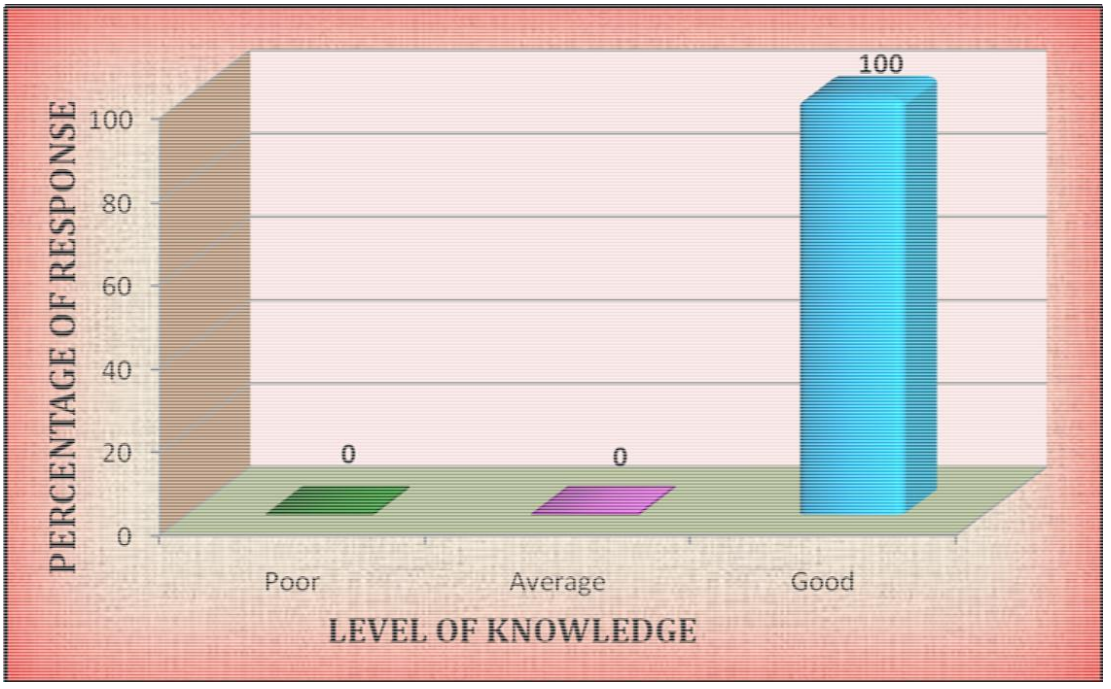


International Journal of Trend in Scientific Research and Development (IJTSRD) ISSN: 2456-6470

Figure 12: Bar diagram showing Percentage distribution of respondents according to their level of posttest knowledge

The above graph shows that $100 \%$ of menopausal women had good Knowledge regarding osteoporosis and its management in the post-test.

\section{Distributions of area-wise mean standard deviation and mean percentage of knowledge scores-post-test}

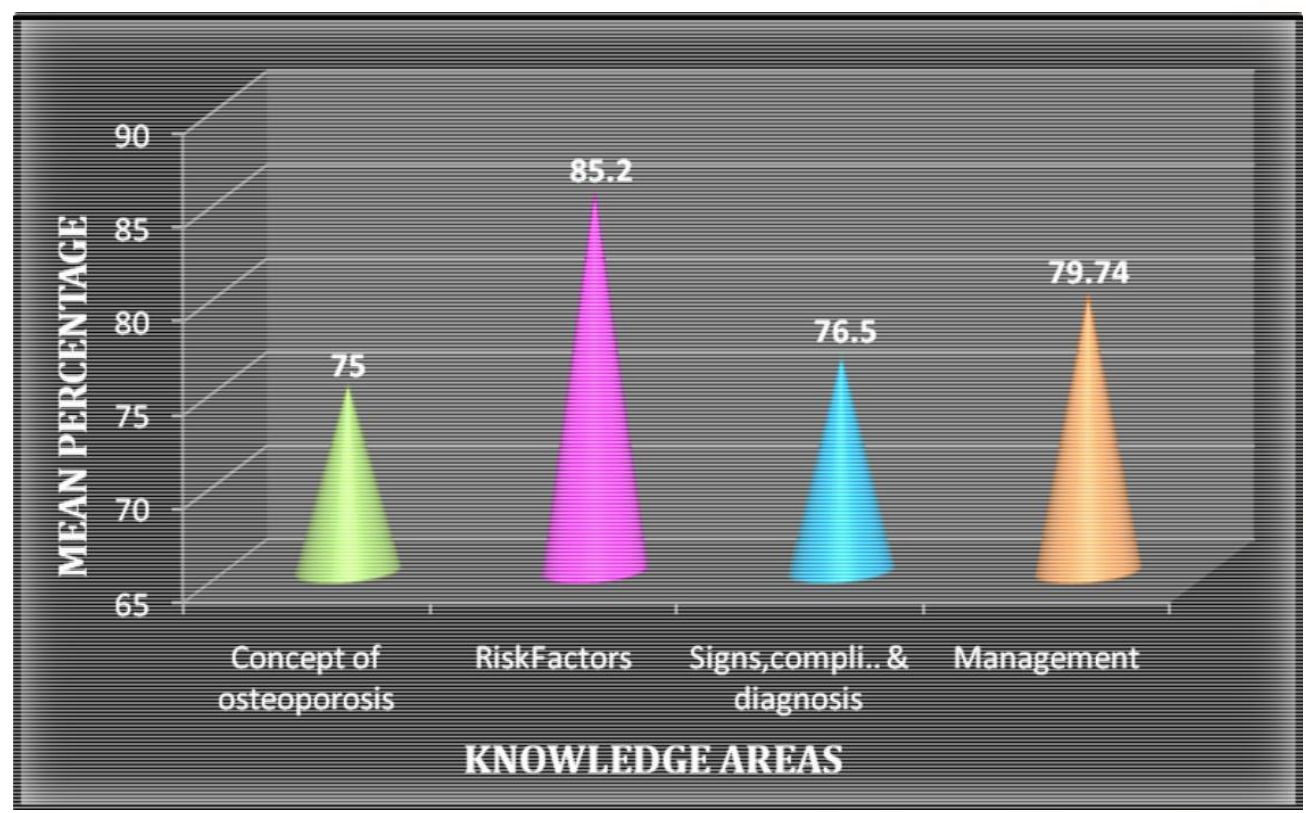

Figure 13: Cone diagram showing Percentage distribution of post-test knowledge score of menopausal women

The above graph shows that the highest mean percentage (85.2\%) of knowledge score was in the area of "Risk factors of Osteoporosis" which had a mean \pm standard deviation as $4.26 \pm 0.694$. The mean percentage in the area of "management of Osteoporosis" was $79.74 \%$ with mean \pm standard deviation as $11.96 \pm 1.484$. The mean percentage in the area of "Signs and symptoms, complications and diagnosis of Osteoporosis" was 76.5\% with mean \pm standard deviation as $3.06 \pm 0.586$. The mean percentage in the area of "concept of Osteoporosis" was $75 \%$ with mean \pm standard deviation as $3 \pm 0.639$. However, the mean percentage of total knowledge score was 79.57 with mean \pm standard deviation of $22.28 \pm 2$. The findings reveal that the knowledge of menopausal women regarding Osteoporosis and its management was good in all the areas.

\section{Comparison of pre-test and post-test knowledge scores of menopausal women}

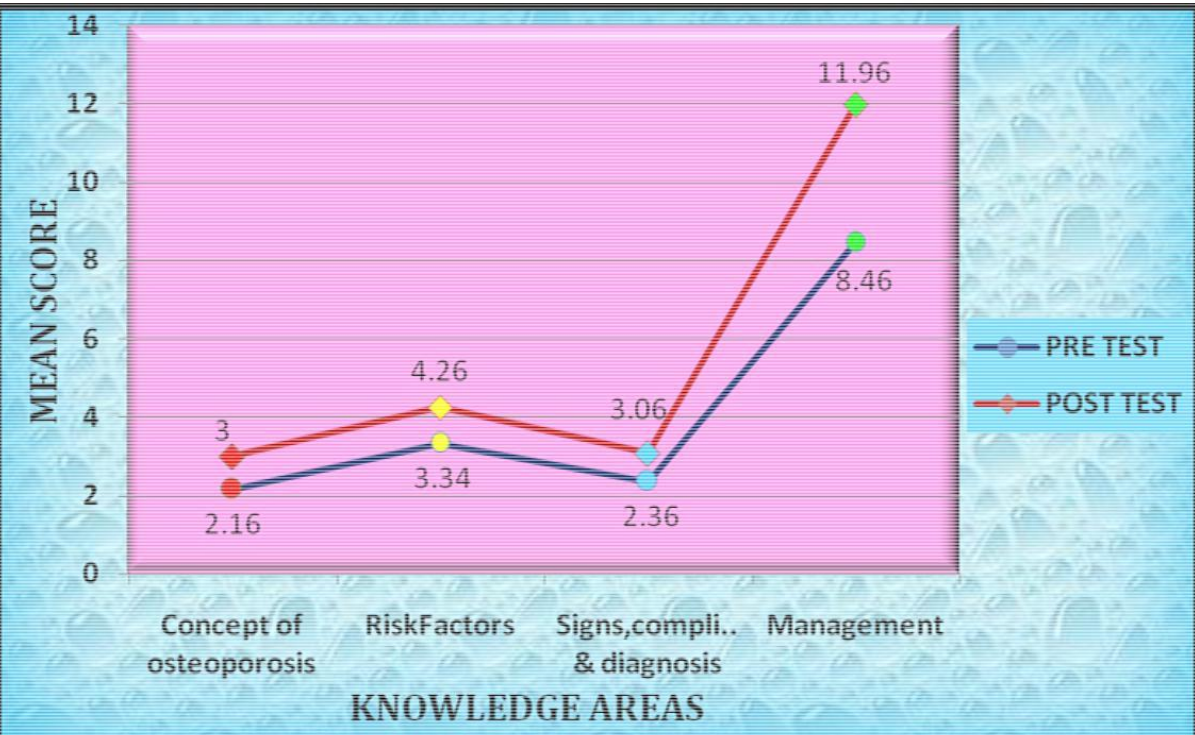


International Journal of Trend in Scientific Research and Development (IJTSRD) ISSN: 2456-6470

Figure 14: Line graph showing Comparison of pre-test and post-test knowledge scores of menopausal women

The data presented in the Figure 14 shows that there is an increase in the knowledge scores of menopausal women after the administration of STP. In the pre-test maximum number of respondents (39) scored between10 to 18 , whereas in the post-test maximum number of respondents (50) scored between 19 to 28 . Hence the findings show that STP was highly effective.

Table 1: Area-wise effectiveness of the STP on knowledge of osteoporosis and its management

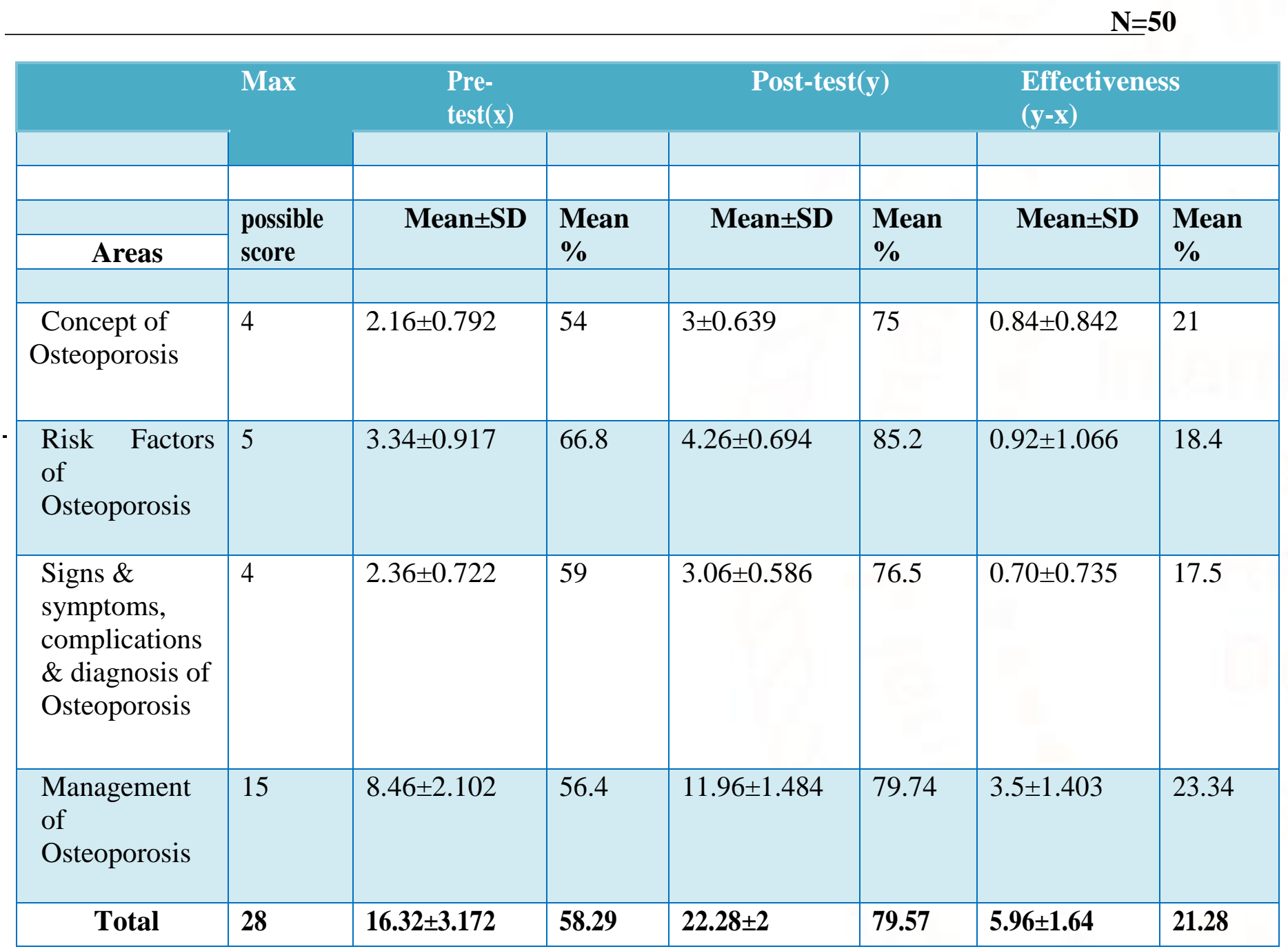

The table 1 shows the Comparison of area-wise mean and SD of the knowledge scores that in the area of' "Concept of Osteoporosis" the pre-test mean percentage was 54 where as the post-test mean percentage was 75 showing an increase of 21 in the mean knowledge score of the menopausal women. The effectiveness of the STP was $18.4 \%$ in the area of "Risk factors of Osteoporosis", $17.5 \%$ in the area of signs \& symptoms, complications and diagnosis of Osteoporosis, 23.34\% in the area of management of Osteoporosis respectively. However, overall findings revealed that the mean percentage of post-test knowledge score was higher compared to the pre-test knowledge score. Hence, it is observed that the STP was effective in all the areas. 
Table 2: Significance of the difference between pre-test and post-test knowledge scores

\begin{tabular}{|l|l|l|l|l|l|l|l|}
\hline Knowledge & & Standard & ' $t{ }^{\prime}$ & & Table & & \\
\hline Score & Mean & deviation & value & & value & P value & Inference \\
\hline & & & & & & & \\
\hline Pre-test & 3.172 & & & & & \\
\hline & & & 25.685 & 1.6755 & $\mathrm{P}<0.05$ & Significant \\
\hline Post-test & 2.000 & \multicolumn{5}{|l|}{} \\
\hline
\end{tabular}

The above table 2 revealed that the mean post-test score of menopausal women were significantly higher than their mean pre-test score. The calculated ' $t$ ' value was greater than the table value at $5 \%$. Hence the null hypothesis $\mathrm{H}_{01}$ (statistical hypothesis) was rejected and research hypothesis $\mathrm{H}_{1}$ was accepted indicating that the gain in knowledge was not by chance. Therefore, it is concluded that the gain in knowledge of menopausal women through the structured teaching programme on osteoporosis and its management was significant.

Table 3: Chi-square value for selected demographic variables and mean pre-test knowledge scores

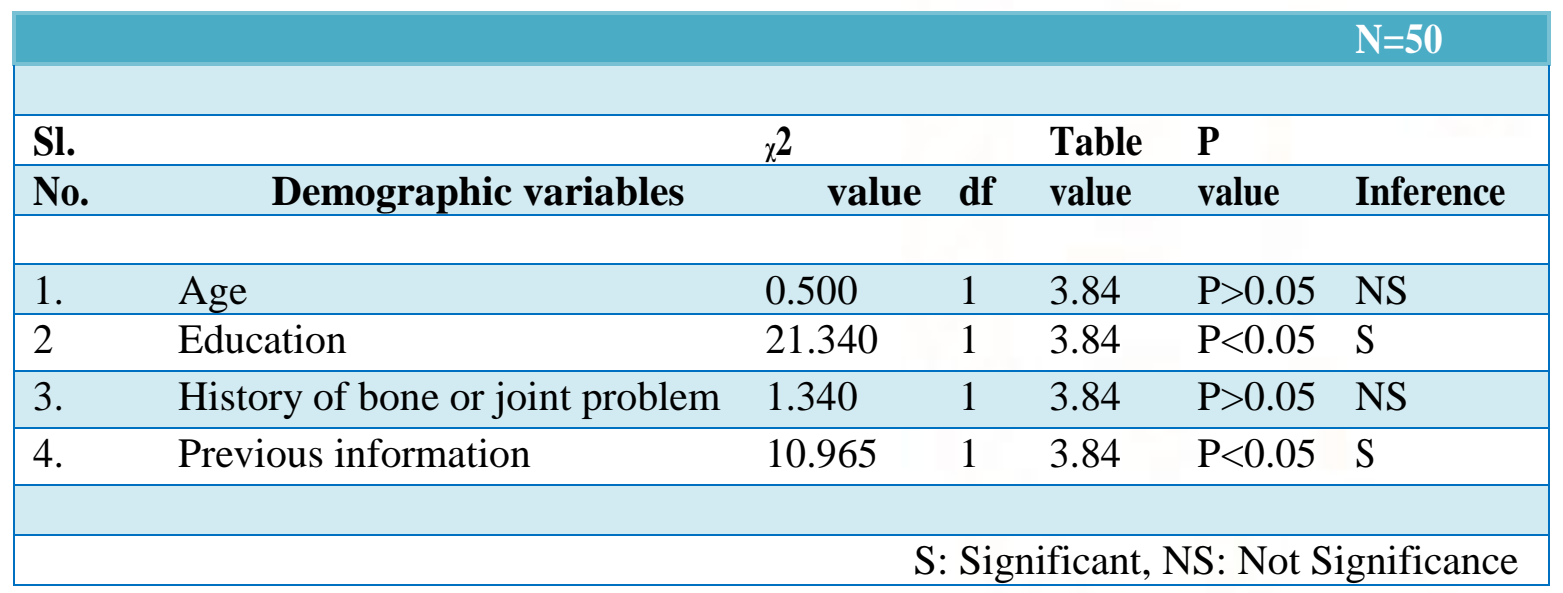

The data presented in table 3 shows that there was a significant association between the demographic variables such as education and previous information about osteoporosis and the pre- test knowledge scores at 0.05 level of significance. But the other demographic variables such as age and history of bone or joint problem do not shows statistical association with level of knowledge regarding osteoporosis and its management.

\section{Implications}

The findings of the study have implications in various areas of nursing education, nursing practice, nursing research and nursing administration.

\section{Nursing education}

There is a need for continuing education offerings to inform community nurses about osteoporosis prevention, detection, and management. While planning the curriculum, the nurse educators should encourage the students to participate in the public health education programme and expose them to develop booklet, handouts or role plays on osteoporosis and its management.

\section{Nursing practice}

Community nurses can play a significant role in supporting individuals in making these positive choices. Additionally health care providers can identify high-risk individuals and follow up with screening and treatment when appropriate. An osteoporosis educational programme can increase 
women's knowledge levels and change their health beliefs about osteoporosis and preventive behaviours.

\section{Nursing research}

Various methods may be used to strengthen the knowledge of the people by researches, which should be published for the benefit of those who are not able to participate in the study.

There is a great need for more research with various samples and different age groups. The challenge remains in turning knowledge gained from health education into lifelong practices and adopting new health behaviours.

\section{Nursing administration}

Continuing education and nursing education about osteoporosis need to be highly valued. Community health administrators should evaluate learning needs and provide continuing education via multiple channels. Nursing educators should reassess and reconstruct nursing curricula. Symptoms/signs, diagnosis, prevention and management issues are suggested as the core components of designing nursing curricula and continuing education on osteoporosis.

\section{DISCUSSION \& CONCLUSION}

On the basis of the findings of the study, the following conclusions are drawn. Distribution of menopausal women according to their knowledge regarding osteoporosis and its management shows that $78 \%$ of them had average level of knowledge, $22 \%$ of them had good level of knowledge.

Highly significant difference $(\mathrm{t}=25.685, \mathrm{P}<0.05)$ was found between pre-test and post- test knowledge scores of samples in the areas of osteoporosis and its management. The study revealed that the STP on osteoporosis and its management was very highly effective in improving the knowledge of menopausal women on osteoporosis and its management.

A similar study was done to test the effectiveness of an educational intervention to increase dietary intake of calcium and vitamin D in young adult females aged 19-30. Study participants were 80 females. The result of the study showed that the mean pre-test knowledge was $35.9 \%$ and the mean post-test knowledge was $81.2 \%$ among the study group. This study concluded that the STP was effective in improving the knowledge about knowledge of osteoporosis, calcium and vitamin $\mathrm{D}^{10}$
Therefore, it is concluded that the gain in knowledge of menopausal women through the structured teaching programme on osteoporosis and its management was very highly significant

Another cross-sectional study was conducted to assess knowledge and factors associating knowledge about osteoporosis in postmenopausal women undergoing antiresorptive treatment in Brazil with 232 samples. Knowledge of osteoporosis was assessed by means of the OPQ. Bivariate analysis showed that education ( $p$ $<0.01)$ is most closely associated with greater knowledge. Hence the study revealed that level of education was a strong predictor of knowledge ${ }^{11}$

\section{REFERENCES}

1. Health Quote Garden. http://www.quotegarden.com/health.html

2. Brunner and suddarth's text book of medical surgical nursing $.12^{\text {th }}$ edition. Volume I, publicated by wolters kluwer (India) pvt.Ltd, New delhi Pp 2062.

3. Joyee M.black. Text book of medical and surgical nursing, $7^{\text {th }}$ edition volume-I, Elsevier publication 2004. Pp 1846.

4. WWW. Google .com/ information on osteoporosis / disease facts. Htm

5. Lamichhane AP. Oteoporosis an update, TU teaching Hospital , Maharajgunj, Kathmardu , Nepal. 2005 April- juine : 44(158): 60-6.

6. World health organ, prevention and management of osteoporosis. 2003; 921:1-164.

7. WWW. Gooogle .com / prevalence of osteoporosis in worldwide.

8. WWW. Google .com / prevelance of osteoporosis in india.

9. Handa R . management of osteoporosis, osteoporosis society of India , All Indian Institute of medical sciences, New delhi, India. 2005, April-june: 44(158):66-6

10. Bohaty K, Rocole $\mathrm{H}$, Wehling $\mathrm{K}$, Waltman N. Testing the effectiveness of an educational intervention to increase dietary intake of calcium and vitamin $\mathrm{D}$ in young adult women. $\mathrm{J}$ Am Acad Nurse Pract [serial on the Internet]. 2008 Feb [cited 2011 Jul 5];20(2):[about 7 p.]. Available from: http:// www.ncbi.nlm.nih.gov/pubmed/18271764

11. Paiva CL, Gomes CD, Morais SS, Pedro OA, Pinto MA. Knowledge about osteoporosis in postmenopausal women. Maturitas [serial on the Internet]. 2011 May [cited 2011 Jun 17];69(1):[about 5 p.]. Available from: http:// www.maturitas.org/article/S0378-5122(11) 00042-9 